\title{
Sustainable Fashion- The Most Popular Textile of the Spring Summer 2020 Season
}

\author{
Feng Yaming* \\ Shih Chien College of Design and Management, Taiwan
}

*Corresponding author: Feng Yamin, Professor, Shih Chien College of Design and

Management, Taiwan.

Received Date: March 03, 2020

Published Date: March 06, 2020

\section{Editorial}

Fabric is the core of fashion business. Great designs were futile without a fine fabric. So, what kind of innovative fabric could be brought up and win the applause by the end of Spring Summer 2020 Fashion Week the most? The answer is neither graphic pattern nor embroidery but "Sustainable Fashion". It has now become a hot topic, and so as for both fashion buyers and editors.

To be environmentally friendly has taken more and more important part of fashion business since people realize by times that the natural resources are not unlimited. This issue was first proposed by a British fashion designer, Stella McCartney: People buy new items seasons by seasons, but have them ever think of how to deal with those old ones? Stella McCartney has spent more than 10 years promoting the use of recycled materials vigorously. Furthermore, she puts reuse into practice by insisting on using recycled nylon fabrics instead of animal fur as handbag design material, and using "Vegan Leather", which is made of resin from natural aquatic plants, as leather shoes design material, and so on.

To put it briefly, sustainable fashion refers to longevity fabric that has much less resource in water, energy and chemicals than traditional materials need to produce or grow.

The achievements of "Sustainable Fashion" finally result on the Spring Summer 2020 fashion show in 2019. As the garden landscaping on the Dior show will be transfer to local urban gardening; the gorgeous lighting on the Saint Laurent show are charged by renewable electric energy in order to generate electricity; and even H\&M, that has never listed in brands of environmental protection before, has launched its "Conscious" series. "Conscious" design is a series of affordable sustainable fashion, which is famous by its fabric's material, like waste polyester bottles and recyclable organic cotton.

Marine Serre, a new star on the fashion runway, is also one of the followers of sustainable fashion. Marine applies many natural materials to his works, such as natural dyes and recycled weaving. As well as the jewelry that went with the garment on the show is natural driftwood or shells that picking up at the beach. All those raw-material-originated jewelries has been marked under the spotlight with their plain but unique look.

Nevertheless, fabrics are still the first step of fashion business no matter we choose to use natural materials or sustainable materials or not. Choosing to be fashionable and environmentally friendly at the same time will be an important subject for men and women in the 21 st century.

\section{Acknowledgement}

None.

\section{Conflict of Interest}

Authors declare no conflict of interest. 